\title{
Urinary Estriol as an Index of Placental Function
}

\author{
Hisao Aoba \\ Department of Obstetries and Gynecology (Prof. K. Kushima), \\ Tohoku University School of Medicine, Sendai
}

\begin{abstract}
To assess the placental function, urinary excretion of estriol was estimated by the method developed by Kanbegawa. In normal pregnancy the mean urinary estriol always showed high values throughout the pregnancy, whereas in complicated pregnancy such as toxemia, retarded fetal growth and fetal death, it showed low values. Correlation between urinary value of estriol and fetoplacental weight ratio was significant. The value of urinary estriol less than $10 \mathrm{mg} /$ day at term would imply placental dysfunction. Estimation of urinary estriol after administration of Diamox is much useful in the evaluation of the prognosis.
\end{abstract}

Since Aschheim and Zondek ${ }^{1}$ discovered large amounts of estrogenic hormone in urine of pregnant women, a great progress has been made in this field; a lot of estrogenic hormones are present in urine of pregnant women ${ }^{2-4}$ as well as in the placenta. ${ }^{5,6}$ One of the most important functions of the placenta is to produce estrogenic hormones, and their excretion in urine is the major pathway for the elimination of the hormones produced. ${ }^{7}$ The urinary excretion of the estrogens in pregnancy increases some thousand-fold at term. ${ }^{8}$ Ninety per cent of the excreted estrogens in urine have been found in the form of sodium estriol glucosiduronate. ${ }^{9,10}$ The feto-placental unit is regarded as the main site of the production of estriol, and the amount of urinary estriol tends to become subnormal when the placenta is small or markedly degenerated as in toxemia, ${ }^{11-13}$ and to decrease in the case of intra-uterine fetal death.12,14-16 Therefore, the estimation of urinary estriol during pregnancy is believed to be an important and useful index of the placental function. However, time-consuming and complicated procedure in measuring estriol has hindered the assessment of the placental function and the evaluation of the prognosis of the pregnancy. For better understanding of placental function, the present author tried an oral administration of Diamox for the purpose of diuresis to the pregnant women with lowered excretion of urinary estriol and estimated the estriol by the simple method developed by Kanbegawa. ${ }^{17}$ The results obtained will be presented in this paper.

Received for publication, March 9, 1966. 


\section{METHODS}

The observations were made at the Department of Obstetrics and Gynecology, Tohoku University Hospital, for a period of from April 1962 to September 1964, in 212 subjects selected chiefly from the out-patients who had been under prenatal examination, and partially from in-patients. The observations were divided into the following series.

1) The observations without the oral administration of Diamox:

a) Normal pregnancy (130 cases): the pregnancy proceeded without clinical complications and terminated spontaneously in between 38 to 42 weeks with the birth of a healthy baby weighing over $2,500 \mathrm{~g}$.

b) Pregnancy with immature baby (20 cases): the pregnancy was usually uneventful and terminated after 38 weeks with the birth of a live baby weighing less than $2,500 \mathrm{~g}$.

c) Twin pregnancy ( 1 case).

d) Complicated pregnancy such as toxemia (43 mild and severe cases), intrauterine fetal death (1 case), retarded intra-uterine fetal growth (1 case), Rh incompatibility ( 3 cases), and prolonged pregnancy (5 cases).

2) The observations after the oral administration of Diamox:

a) Normal pregnancy.

b) Complicated pregnancy such as severe toxemia, intra-uterine fetal death, retarded intra-uterine fetal growth and prolonged pregnancy.

Urinary specimen: Urine was collected for 24 hours. Some patients with a suspicion of the placental dysfunction were instructed to collect $a_{2} 24$ hour urine and to take one tablet of Diamox (2-acetylamino-1, 3, 4-thiadiazole-5-sulfonamide) early on the following morning and to collect another 24 hour urine.

Method of estimating urinary estriol: $0.8 \mathrm{ml}$ of the 24-hour urine is measured into a $2.0 \times 15 \mathrm{~cm}$ tube, and $40 \mathrm{mg}$ of hydroquinone and then $1.5 \mathrm{ml}$ of concentrated hydrochloric acid are added gradually. The tube is placed in a boiling water-bath for 40 minutes to hydrolyze estrogens, and then cooled in ice water. Three milliliters of distilled water and $8 \mathrm{ml}$ of a $2 \%$ chloroform solution $(\mathrm{w} / \mathrm{v})$ of $p$-nitrophenol are added and the mixture is shaken vigorously twenty times and left in ice water for five minutes. The upper layer is removed by suction, and the optical density of the lower layer is compared with that of a standard estriol solution with a Hitachi 139 type spectrophotometer. Readings ("D") are made at 520 and $540,560 \mathrm{~m} \mu$, and a corrected reading at $540 \mathrm{~m} \mu$ is obtained using Allen's formula as: corrected reading ("E 540") $=$ D 520- $\frac{1}{2}(\mathrm{D} 540+\mathrm{D} 560)$. The estrogen excretion, calculated as $\mu \mathrm{g}$ of estriol per 24 hours is:

$$
\frac{\text { E } 540 \text { of urine }}{\text { E } 540 \text { of standard }} \times \frac{\text { Volume of } 24 \text { hour urine specimen }}{\text { Volume of urine analyzed }}
$$




\section{RESULTS}

1) Relationship between pregnancy and urinary estriol

a) Normal pregnancy

One hundred and thirty normal pregnant women were studied and the determination of urinary estriol was done at from the 8th to 41 st week of

TABLE 1. Mean excretion value of estriol per week of pregnancy

\begin{tabular}{c|c}
\hline Pregnancy (week) & $\begin{array}{c}\text { Estriol } \mu \mathrm{g} / 24 \mathrm{hrs} \\
\text { Mean } \pm \text { standard deviation }\end{array}$ \\
\hline $8-12$ & $\mathbf{1 , 6 1 2} \pm 629$ \\
$13-16$ & $3,269 \pm 1,402$ \\
$17-20$ & $4,107 \pm 893$ \\
$21-24$ & $7,277 \pm 861$ \\
$25-28$ & $9,626 \pm 761$ \\
29 & $10,184 \pm 1,542$ \\
30 & $11,776 \pm 2,349$ \\
31 & $12,060 \pm 2,645$ \\
32 & $14,222 \pm 2,129$ \\
33 & $15,915 \pm 2,539$ \\
34 & $16,914 \pm 2,651$ \\
35 & $18,017 \pm 3,363$ \\
36 & $19,667 \pm 3,970$ \\
37 & $22,614 \pm 3,558$ \\
38 & $24,794 \pm 3,464$ \\
39 & $27,366 \pm 2,301$ \\
40 & $25,024 \pm 2,655$ \\
41 & $21,913 \pm 1,839$
\end{tabular}

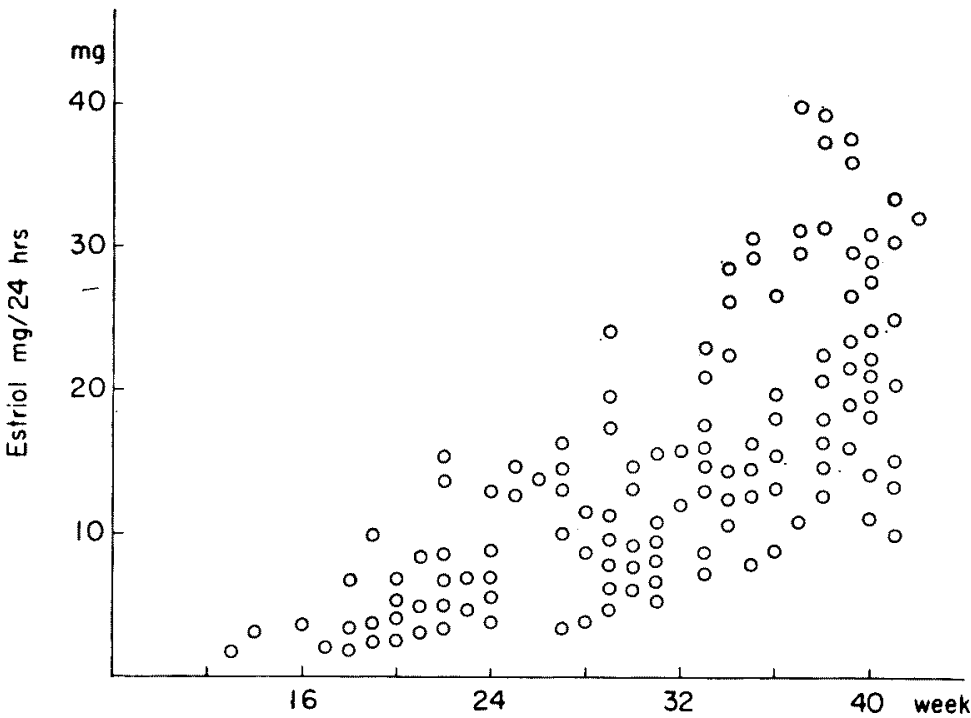

Fig. 1. Urinary estriol during pregnancy in normal group. 
pregnancy. The value of urinary estriol was plotted in Fig. 1 and the values found at various stages of pregnancy were summarized in Table 1. Generally, the estriol excretion increased steadily throughout the normal pregnancy and the mean estriol value reached its maximum value of $27,366 \mu \mathrm{g}$ at the $39 \mathrm{th}$ week of

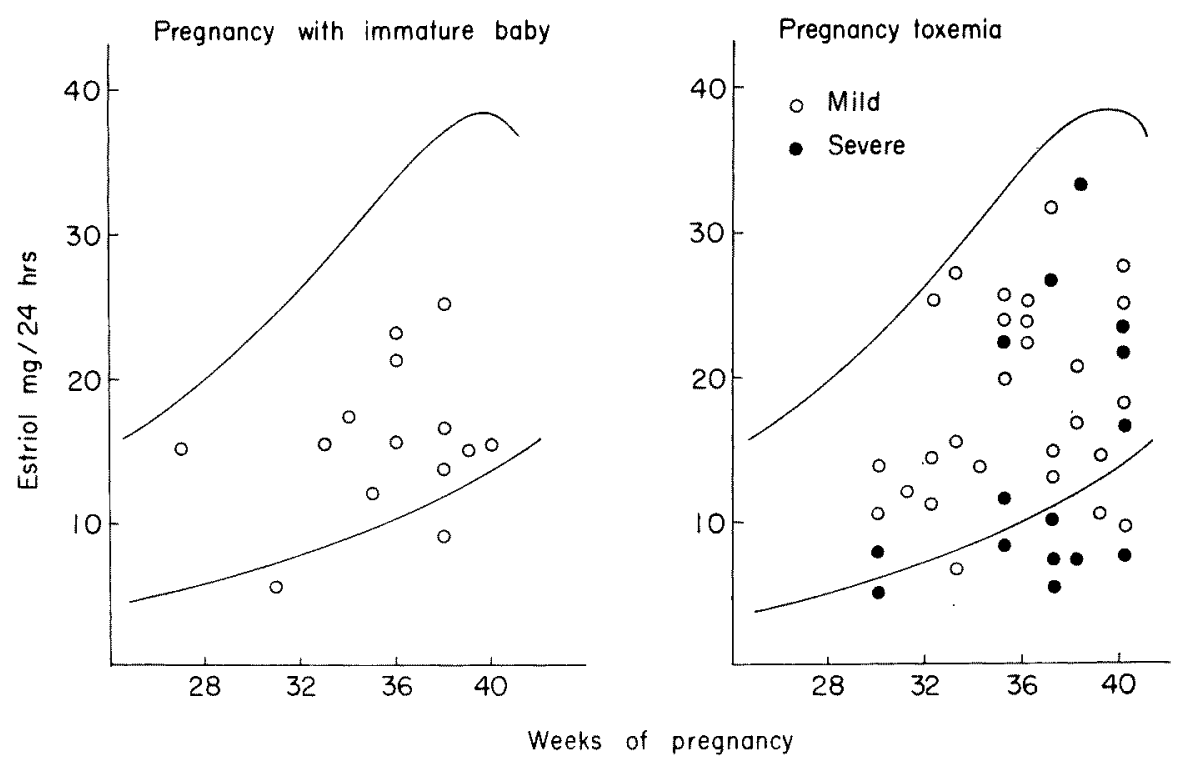

Fig. 2. Urinary estriol in pregnancy with immature baby and in pregnancy toxemia. The upper and lower curves indicate the normal range of variation (see Fig. 1).

TABLE 2. Comparison of urinary estriol before and after the admin. istration of Diamox in uncomplicated pregnancy (12 Cases)

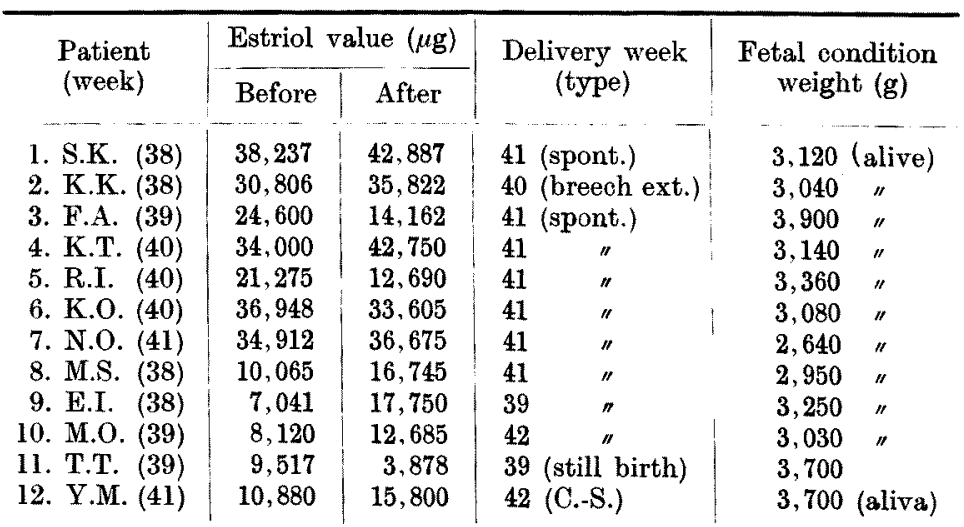


pregnancy. As the pregnancy went on, the variation in estriol value at each week became more remarkable. Consequently, the highest value of estriol was $40,250 \mu \mathrm{g}$ and the lowest one was $9,880 \mu \mathrm{g}$ at the 40 th week.

b) Pregnancies with small babies

Twenty women gave birth to live babies weighing less than $2,500 \mathrm{~g}$ after a gestation period of more than 38 weeks. They showed no complications throughout the pregnancy, and the estriol values were rather similar until the 30 th week to those in the pregnancies with mature babies, but after that period they increased at a slower rate (Fig. 2). The mean value at the 40 th week was $15,260 \mu \mathrm{g}$ and its difference from the normal estriol value $(25,024 \mu \mathrm{g})$ was significant.

c) Complicated pregnancy

Forty-three cases of toxemia were studied and the estriol values were similar to those of the normal pregnancy (Fig. 2) but the value was found to be lower in patients with severe toxemia (Table 3 ) and the mean value at the 40 th week was $15,100 \mu \mathrm{g}$.

TABLE 3. Comparison of urinary estriol before and after the administration of Diamox in severe toxemia (8 Cases)

\begin{tabular}{|c|c|c|c|c|}
\hline \multirow{2}{*}{$\begin{array}{l}\text { Patient } \\
\text { (week) }\end{array}$} & \multicolumn{2}{|c|}{ Estriol value $(\mu \mathrm{g})$} & \multirow{2}{*}{$\begin{array}{l}\text { Dilivery week } \\
\text { (type) }\end{array}$} & \multirow{2}{*}{$\begin{array}{c}\text { Fetal condition } \\
\text { weight }(\mathrm{g})\end{array}$} \\
\hline & Before & After & & \\
\hline 1. T.K. (37) & 10,300 & 15,356 & 38 (spont.) & 2,620 (alive) \\
\hline 2. K.I. (38) & 34,290 & 43, & 39 " & $2,920 "$ \\
\hline 3. T.M. (39) & 10,255 & 16,885 & 40 & 3,060 \\
\hline 4. T.A. $(40)$ & 21,083 & 25,650 & 40 & $3,600 "$ \\
\hline 5. N.S. $(40)$ & 24,937 & 40,000 & 40 (C.-S.) & $3,800 \prime \prime$ \\
\hline 6. N.U. (37) & 7,625 & 14,421 & 38 (spont.) & 2,500 \\
\hline 7. S.S. (37) & 6,567 & 3,705 & 38 (still birth) & 1,900 \\
\hline 8. T.Y. (38) & 7,740 & 14,478 & 40 (spont.) & 3,120 (alive) \\
\hline 9. S.B. (39) & 10,670 & 10,687 & 41 & $1,980 "$ \\
\hline 10. E.S. $(36)$ & 22,668 & 49.674 & 38 & $\begin{array}{l}\text { 1. } 2,680 \text { (both } \\
\text { 2. } 2,540 \text { alive) }\end{array}$ \\
\hline
\end{tabular}

9: retarded intra-uterine growth of fetus 10: twin pregnancy

TABLE 4. Comparison of urinary estriol before and after the administration of Diamox in prolonged pregnancy $(5$ Cases)

\begin{tabular}{|c|c|c|c|c|}
\hline \multirow{2}{*}{$\begin{array}{l}\text { Patient } \\
\text { (week) }\end{array}$} & \multicolumn{2}{|c|}{ Estriol value $(\mu \mathrm{g})$} & \multirow{2}{*}{$\begin{array}{l}\text { Delivery week } \\
\text { (type) }\end{array}$} & \multirow{2}{*}{$\begin{array}{l}\text { Fetal condition } \\
\text { weight }(g)\end{array}$} \\
\hline & Before & After & & \\
\hline h. & & 12, & 43 (spor & 2,580 (ali \\
\hline 2. M.S. (42) & 30 , & 37. & 43 & 3,100 \\
\hline 3. N.K. (42) & 16 & 28, & 43 & 3,800 \\
\hline 4. M.E. (42) & 30 . & 21 , & 43 & 3,570 \\
\hline 5. S.K. (42) & 30,530 & 35,775 & 44 & $2,920 \quad "$ \\
\hline
\end{tabular}


d) Other conditions such as twin pregnancy, retarded intra-uterine fetal growth, fetal death also showed low estriol values as shown in Table 3. The mean value

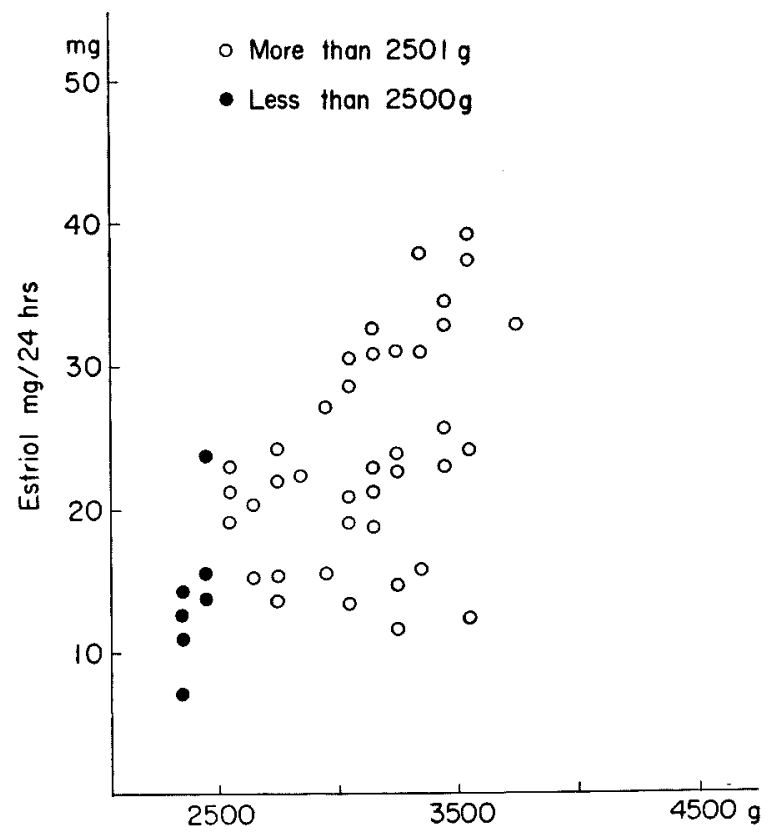

Fig. 3. Urinary estriol and birth weight.

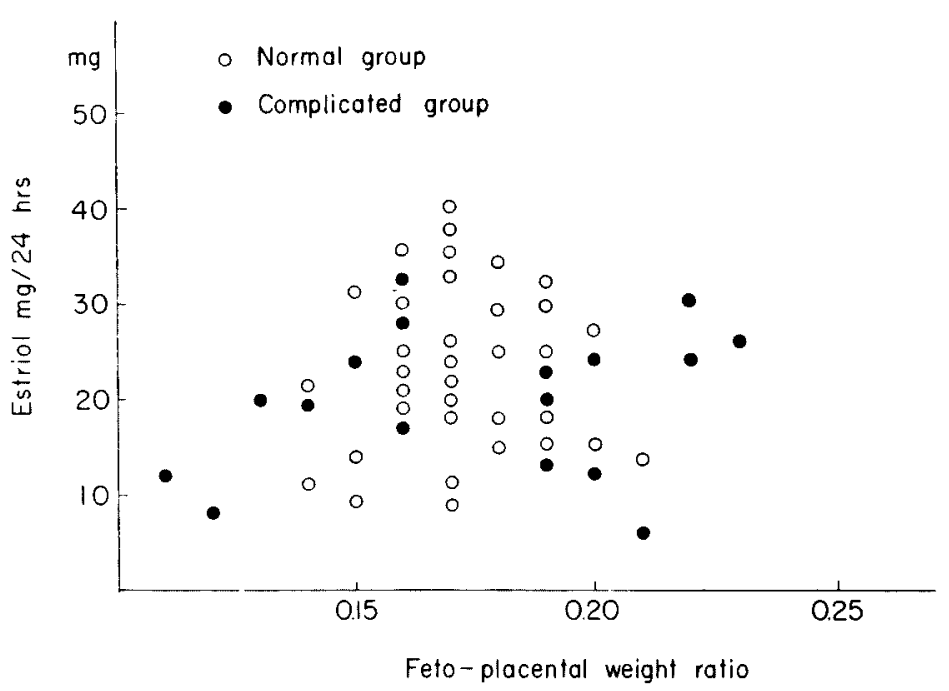

Fig. 4. Correlation of feto-placental weight ratio and urinary estriol. 
of urinary estriol of retarded fetal growth at the 38th week was $10,659 \mu \mathrm{g}$ and that in fetal death was really decreased. Urinary excretion of estriol in prolonged pregnancy was almost the same as in the normal pregnancy (Table 4).

\section{2) Correlation between urinary estriol and the feto-placental unit}

Fig. 3 shows the correlation between fetal weight and urinary estriol excretion in normal and complicated pregnancy, and urinary estriol excretion reflected placental weight as well as fetal weight. In normal pregnancy estriol excretion was found to be related to fetal weight as Fig. 3 shows, and an estriol value of $9,880 \mu \mathrm{g}$ or more was associated with a mature infant. Fig. 4 illustrates the relationship between the urinary estriol excretion and the feto-placental weight ratio in normal and complicated pregnancies. As Fig. 4 shows, the normal pregnant women with the feto-placental weight ratio of 0.17 showed the highest urinary excretion of estriol. The value of the feto-placental weight ratio in normal pregnancy is almost constant, but in the group with complications the value was rather scattered. The weight ratio between 0.15 to 0.20 was regarded as the normal range, and 77.8 per cent of normal cases but only 42.1 per cent of complicated cases were within normal range.

3) Urinary excretion of estriol after the administration of Diamox

Since the minimum value of urinary estriol in normal pregnancy at term

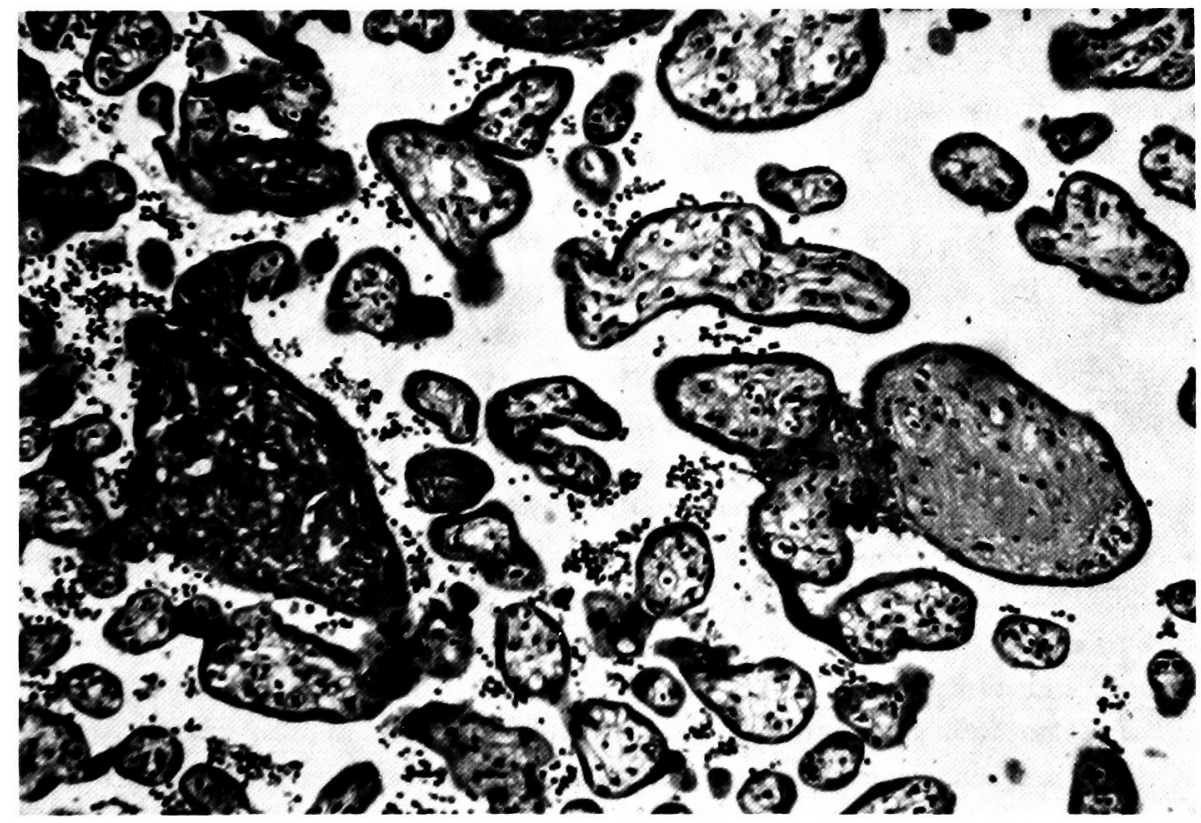

Fig. 5. Placental villi from a case of retarded intra-uterine growth of fetus. Formalin fixation. Hematoxylin and eosin. $\times 125$. 
was $9,880 \mu \mathrm{g}$, placental dysfunction might exist in the cases where the urinary estriol value was under $10 \mathrm{mg} /$ day. Diamox was given to these cases.

a) Normal pregnancy: Five cases showed abnormally low urinary output of estriol before the administration of Diamox, and after the medication 4 of them showed normal estriol values and favorable prognosis. One case had still-birth whose urinary estriol did not rise to a normal value.

b) Complicated pregnancy: Two cases of severe toxemia with abnormally low urinary estriol showed the normal values after the medication and the prognosis was also favorable.

c) Retarded fetal growth: There was no remarkable change after the administration of Diamox, and both baby and placenta were immature (Fig. 5).

d) Prolonged pregnancy: As Table 4 shows, the fetal condition is favorable.

\section{DISCUSSION}

To estimate the placental function, the histo-pathological study of the placenta is one of the adequate approaches to the problem but the histological change sometimes fails to explain a complicated pregnancy.

An important function of the placenta lies in its production of estrogen and the feto-placental unit is regarded as the main source of estrogen. ${ }^{18}$ Recently, the fetal role in the pathway of estrogen metabolism has been proved. ${ }^{20}$ Therefore, it is reasonable to assess the feto-placental function by the estimation of urinary excretion of estriol. Among the results obtained from the present study, the correlation between feto-placental weight ratio and urinary excretion of estriol is interesting. The maximum estriol value was observed in the normal pregnant women whose feto-placental weight ratio was 0.17 . There is no clear explanation to this phenomenon, but to some extent the weight ratio might be a reflexion of proper feto-placental circulation. Cassmer ${ }^{18}$ and Bolté et al. ${ }^{19}$ suggested the importance of proper feto-placental circulation, but the fetoplacental circulation always depends upon the utero-placental circulation. Weis et al..$^{20}$ and Taylor et al. ${ }^{21}$ demonstrated decreased utero-placental circulation in toxemia and in complicated pregnancy, and a remarkable histological change in the spiral artery was found in complicated pregnancy. The present author failed to demonstrate the correlation of the histological change and urinary estriol output in toxemia, but it is possible to assume that some circulatory disturbance would block the metabolic pathway of estrogen. But in the case of retarded fetal growth, both the placenta and the fetus were immature. Especially, the histological change of placenta was remarkable, as Fig. 5 shows.

Diamox was given to nine pregnant women with abnormally low urinary estriol: In six cases with increased urinary estriol the fetal condition was favorable. In one case there was no change of urinary estriol and its baby was immature. In two cases urinary estriol decreased after the medication and the babies died. 
Only the cases of increased estriol had favorable fetal prognosis. From these results, the Diamox loading method would be useful to establish the low urinary excretion of estriol.

\section{References}

1) Aschheim, S. \& Zondek, B. Hypophysenvorderlappenhormon und Ovarialhormon im Harn von Schwangeren. Klin. Wschr., 1927, 6, 1322.

2) Doisy, E.A. \& Thayer, S.A. The preparation of theelol. J. biol. Chem., 1931, 91, 641-645.

3) Marrian, G.F. The chemistory of oestrin. Preparation from urine and separation from an unidentified solid alcohol. Biochem. J., 1929, 23, 1090-1098.

4) Doisy, E.A., Thayer, S.A., Levin, L. \& Curtis, J.M. A new tri-atomic alcohol from the urine of pregnant women. Proc. Soc. exp. Biol. Med., 1930, 28, 88-89.

5) Westfeld, W.W., Thayer, S.A., Doisy, E.A. \& Mac Corquodale, P.W. The isolation of theelin from human placenta. J. biol. Chem., 1938, 126, 195-200.

6) Huffman, M.N., Thayer, S.A. \& Doisy, E.A. The isolation of $a$-dihydro-theelin from human placenta. J. biol. Chem., 1940, 133, 567-571.

7) Brown, J.B. The relationship between urinary oestrogens and oestrogens produced in the body. J. Endocr., 1957, 15, 202-212.

8) Eastman. N.J. \& Hellman, L.M. Williams obstetrics. Appleton-Century-Crofts. Inc., New York, 1961, p. 179.

9) Cohen, S.L., Marrian, G.F. \& Watson, M. Excretion of oestrogen during pregnancy. Lancet, 1935, 228, 674-676.

10) Doisy, E.A. The preparation of theelol. J. biol. Chem., 1931, 91, 641-654.

11) Kellar, R., Matthew, G.D., Mackay, R., Brown, J.B. \& Roy, E.J. Some clinical applciations of estrogen assays. J. Obstet. Gynaec. Brit. Emp., 1959, 66, 804-814.

12) Bernhard, Z. \& Vera, P. Further studies on urinary oestriol excretion during pregnancy and its significance for estimation of placental function and dysfunction in advanced pregnancy. Acta obstet. gynec. scand., 1959, 38, 742-761.

13) Furuhjelm, M. The excretion of oestriol and pregnanediol in toxemia of pregnancy and in postmaturity. Acta obstet. gynec. scand., 1962, 41, 370-381.

14) ten Berg, B.S. Estriol excretion in intrauterine fetal death: Significance of sudden decrease and its relation to capillary pressure in villi. Gynecologia (Basel), $1960,149,40-55$.

15) Green, J.W., Touchstone, J.C. \& Fields, H. Urinary estriol as an index of placental function. Acta endocr. $(K b h)$., 1960, Supp. 51, 1119.

16) Frandsen, J.A. \& Stakemann, G. The site of production of oestrogenic hromones in human pregnancy. Acta endocr. $(K b h)$., 1961, 38, 383-391.

17) Kanbegawa, A. \& Hosokawa, T. Measurements of estrogens. Endocrinology, Metabolism. (Jap.), 1962, 3, 217-218.

18) Cassmer, 0 . The role of fetal circulation with regard to the elaboration of estrogenic hormones on the placenta. Acta endocr. $(K b h)$., 1959, Supp. 45, 59-73.

19) Boltè, E., Mancuso, S., Eriksson, G., Wiqvist, N. \& Diczfalsy, E. Studies on pregnant women. Acta endocr. $(K b h) ., 1964,45,535-559$.

20) Weis, E.B., Bruns, P.D. \& Taylor, E.S. A comparative study of the disappearance of radioactive sodium from human uterine muscle in normal and abnormal pregnancy. Amer. J. Obstet. Gynec., 1958, 76, 340-346. 
21) Taylor, E.S., Bruns, P.D. Hepner, H.J. \& Drose, V.E. Measurements of placental function. Amer. J. Obstet. Gynec., 1958, 76, 983-997. 